\title{
LA PERSPECTIVA GENEALÓGICA NIETZSCHEANA Y LA ESCRITURA DE LA HISTORIA
}

\author{
Óscar MORO ABADÍA \\ Universidad de Cantabria
}

Resumen: El presente artículo propone una definición de la perspectiva genealógica de F. Nietzsche (1844-1900) a través de la interpretación que de ella realizara Michel Foucault (1926-1984). Dicha perspectiva, convertida en una critica de los valores, se constituye como instrumento del análisis histórico a través de tres de las líneas fundamentales que la definen: la critica del fundamento metafisico de la historia, la crítica del origen como lugar de la esencia y la pregunta por el valor de la verdad y de lo verdadero. El seguimiento de esas lineas y una definición global de la perspectiva genealógica es el objeto de este trabajo.

Abstract:This article proposes a new understanding of Friedrich Nietzsche's Genealogical Perspective, from the standpoint of Michel Foucault's interpretation of Nietzsche's work. That perspective, based upon a critical review of moral values, is defined as an instrument of Historical Analysis along three different lines: the critique of the metaphysical foundations of History, the critique of ideal origins (i.e. the place from which the essence of things originates), and the question of the value of truth. The examination of these three themes and the construction of a broad definition of the Genealogical Perspective is the primary objective of this essay.

\section{Introducción}

Valorar el tamaño de la herida que el pensamiento «a golpe de martillo" de Friedrich Nietzsche (1844-1900) provocó en la epidermis del saber occidental, se convirtió en una de las tareas fundamentales de la filosofía del siglo XX. Para hacerse una idea de la importancia de este hecho, basta repasar el ilustre nom- 
bre de alguno de los analistas del filósofo de $\mathrm{R}^{\wedge}$ cken: Heidegger, Jaspers, Deleuze, Colli, Danto, Bataille, etc. Sin embargo, quizá estemos en un momento en el que, en lugar de aspirar a una interpretación general (casi siempre pervertida en hermenéutica), haya que abrir nuevos espacios a través de las líneas que nacen de la conexión de Nietzsche y de sus intérpretes. El seguimiento de una de ellas, la que va desde Nietzsche a Foucault y toma el nombre de genealogía ${ }^{1}$, me ha ocupado en los últimos tiempos. Aunque mi trabajo ha consistido en un análisis relativamente concreto (una lectura del discurso sobre el pasado remoto en clave genealógica) creo pertinente esbozar ahora una definición general de lo que el pleno desarrollo de la "perspectiva genealógica" puede significar para el análisis historiográfico.

Señalado por muchos, el triángulo que forman estos tres vértices (Nietzsche-Genealogía-Foucault) no ha merecido sin embargo demasiados estudios monográficos. De dicha escasez nace el interés de este artículo: proponer una introducción a la perspectiva genealógica nietzscheana a través de la lectura que de ella realizó Michel Foucault ${ }^{2}$. En este sentido, dos

1 Es el propio Foucault quien define una línea, la genealogia, que vincula su pensamiento con el de Nietzsche. (Así por ejemplo, en su última entrevista afirmaba: "Soy simplemente nietzscheano e intento ver, en la medida de lo posible y sobre un cierto número de puntos, con la ayuda de los textos de Nietzsche - pero también con tesis antinietzscheanas (iqué son a pesar de todo nietzscheanas!) - lo que se puede hacer en tal o tal campo. No busco ninguna otra cosa, pero esto lo busco verdaderamente", en: FOUCAULT, MICHEL (1984), "El retorno de la moral», Estética, ética y hermenéutica. Otras esenciales, Volumen III, Paidós, Barcelona, 1999, p. 388.) Dicha filiación es advertida muy claramente por Jürgen Habermas, quien considera que la crítica nietzscheana a la modernidad se traslado al siglo XX a través de dos vías: Una crítica de la metafisica que pretende poner al descubierto las raíces de ésta sin considerarse a sí misma filosofía (estrategia proseguida por Heiddeger y Derrida) y una segunda línea que pretende desenmascarar la voluntad de poder a través de una genealogía de la fe en la verdad. Aquí Habermas incluye a Bataille, Lacan y Foucault, en HABERMAS, JÜGEN (1985), El discurso filosófico de la modernidad, Taurus, Madrid, 1989, p. 125.)

2 Muchos son los textos en los que Goucault hace referencia a Nietzsche. Sin embargo, en lo referente a la perspectiva genealógica tres son los fundamentalesN FOUCAULT, M. (1967), "Niezzsche, Freud y Marx" en Nietzsche, cahier de Royaumont, Philosophie, tome IV, Seuil, 1967, pp. 183-200. (Hay traducción castellana: Nietzsche, Freud, Marx, Anagrama, Barcelona, 1970); FOUCAULT, M. (1971) "Nietzsche, la généalogie, l'historie», Hommage d̀ Jean Hyppolite, P.U.F., París, pp. 145-172. (Hay traducción castellana: Nietzsche, la Genealogia, la Historia, PreTextos, Valencia, 1988) y FouCAULT, M. (1974): "A verdade e as formas jurídicas" (conferencias que tuvieron lugar en la Universidad Carólica de Río de Janeiro, del 21 al 25 de mayo de 1973), Cuadernos da P.U.C., n. ${ }^{\circ} 16$, junio de 1974, pp. 5-133. (Hay traducción castellana: «La verdad y las formas jurídicas", Estrategias de poder. Obras esenciales. Volumen II, Paidós, Barcelona, 1999, pp. 169-281). 
son los calcos que, al superponerse, determinan el espacio de nuestra propuesta: la mencionada interpretación foucaultiana y las consecuencias que para la lectura/ escritura de la historia pueden derivarse del enfoque genealógico.

Toda vez definido el perímetro, conviene plantearse sin más dilación la cuestión que nos atañe y a la que este artículo pretende dar respuesta: øQué es la genealogía? Comenzaré por una respuesta negativa: la genealogía no es ni una teoría ni una metodología. Frente a los rigores del sistema, frente a la exigencia de coherencia de un corpus organizado, la genealogía se realiza en el aforismo (en el relámpago, que diría Colli), estilo filosofico nietzscheano por excelencia. El aforismo se convierte en una ruptura deliberada del universo de lo unitario, un intento de convertir lo múltiple en sustantivo ${ }^{3}$. Es por ello, creo yo, que no cabe hablar de genealogía como Teoría (con mayúsculas). Más bien se trata de un conjunto heterogéneo de sugerencias que definen una perspectiva o enfoque genealógico. Como dijo Derrida del estructuralismo, la genealogía es «una aventura de la mirada, una conversión en la manera de cuestionar ante todo objeto" ${ }^{4}$. La ruptura que introduce dicha perspectiva está, pues, relacionada con el gesto de la interrogación.

Esa perspectiva o mirada (dirigida hacia los objetos históricos) se ejecuta en un doble movimiento: genealogía quiere decir a la vez «la filosofía de los valores, [...] la verdadera realización de la crítica, la única manera de realizar la crítica total, es decir, de hacer filosofía a "martillazos" "5 $\mathrm{y}$, al mismo tiempo, significa "la expresión activa de un modo de existencia activo» ${ }^{6}$. La critica en Nietzsche no es una reacción, es una acción. Genealogía es, por tanto, crítica y acción, inseparables en la mixtura de lo concreto.

3 En Nietzsche hay una relación muy clara entre estilo y multiplicidad: "Voy a añadir ahora algunas palabras generales sobre mi arte del estilo. Comunicar un estado, una tensión interna del pathos, por medio de signos, incluido el tempo [ritmo] de esos signos - tal es el sentido de todo estilo; y teniendo en cuenta que la multiplicidad de estados anteriores es en mí extraordinaria, hay en mí muchas posibilidades de estilo-, el más diverso arte del estilo de que un hombre ha dispuesto nunca.» En NIETZSCHE, FRIEDRICH (escrito en 1889 y publicado en 1908), Ecce homo. Cómo se llega a ser lo que se es, Alianza, Madrid, 1993, p. 61.

4 DERRUDAM JACQUES (1967), La escritura y la diferencia, Anthropos, Barcelona, 1989, p. 9.

5 Deleuze, Gilles (1967), Nietzsche y la filosofia, Anagrama, Barcelona, 1971, p. 7.

6 Idem, p. 9. 


\section{La Genealogía, una crítica de los valores}

La pregunta por la posición de los valores se encuentra en la propia base de la perspectiva genealógica ${ }^{7}$ : su incursión en el ámbito de lo filosófico supone convertir la filosofía en una crítica. De este modo, podemos decir que la genealogía es, ante todo, una crítica de los valores. Y esto en un doble sentido:

- Por un lado se someten los valores a la crítica. Frente a aquellos que realizan la crítica de la Historia desde los valores establecidos (aceptando su carácter verdadero), Nietzsche propone comenzar cuestionando dichos valores ${ }^{8}$; es decir, plantearse su valor, atreverse a "medirnos con el problema del sentido y la cuestión de los valores» 9: «Una exigencia nueva elevará la voz. Enunciémosla: necesitamos una crítica de los valores morales, hay que poner alguna vez en entredicho el valor mismo de esos valores" ${ }^{10}$.

- Por otro lado, Nietzsche lucha "contra los que critican, o respetan, los valores haciéndolos derivar de simples hechos, de pretendidos hechos objetivos" ${ }^{11}$, contra la voluntad de " aquel querer-detenerse ante lo real, ante el factum brutum, aquel renunciar del todo a la interpretación (al violentar, reajustar, recortar, omitir, rellenar, imaginar, falsear y a todo lo demás que pertenece a la esencia del interpretar)» ${ }^{12}$. Nietzsche introduce la idea de la Historia

7 Varios son los autores que han definido el pensamiento nietzscheano como una "filosofía de los valores». Así por ejemplo, en opinión de Deleuze, "el proyecto más general de Nietzsche consiste en eso: introducir en filosofia los conceptos de sentido y valor» en DELEUZE, GiLles (1967), Nietzsche y la filosofia, Anagrama, Barcelona, 1971, p. 7. Heidegger coincide en esta idea: “Lo que importa en la filosofía, para Nietzsche, es una posición de valores, es decir, la posición de los valores supremos de acuerdo con los cuales y a partir de los cuales se determinará cómo debe ser todo ente». En HEIDDEGER, MARTIN (1961), Nietzsche, Destino, Barcelona, 2000 , p. 37.

8 En opinión de Heidegger, esta tarea es fundamental: "Crítica de los valores supremos válidos hasta el momento quiere decir propiamente: aclarar el cuestionable origen de las correspondientes valoraciones y demostrar, de ese modo, la cuestionabilidad de esos valores mismos", Idem, p. 38.

9 NiETzSCHE, FRIEDRICH (1873), Sobre la utilidad y el perjuicio de la bistoria para la vida. II Intempestiva, Biblioteca Nueva, Madrid, 1999, p. 18.

10 NIETZSCHE, FRIEDRICH (1887), La genealogia de la moral. Un escrito polémico, Alianza Editorial, Madrid, 1995, p. 23.

11 Deleuze, Gille (1967), Nietzsche y la filosofla, Anagrama, Barcelona, 1971, p. 8.

12 NIETSCHE, FRIEDRICH (1887), La genealogia de la moral. Un escrito polémico, Alianza Editorial, Madrid, 1995, pp. 173-174. 
como construcción y propone la necesidad del estudio crítico del proceso constitutivo. De este modo, se abren las puertas a una Historia diferente a aquella defendida por Ranke quien, «en el cuarto decenio del siglo XIX, apuntaba que la tarea del historiador era mostrar lo que realmente aconteció (Wie es eigentlich gewesen)» ${ }^{13}$. Para Nietzsche, «existe únicamente un ver perspectivista, únicamente un "conocer" perspectivista; y cuanto mayor sea el número de afectos a los que permitamos decir su palabra sobre una cosa, cuanto mayor sea el número de ojos, de ojos distintos que sepamos emplear para ver una misma cosa, tanto más completo será nuestro "concepto" de ella, tanto más completa será nuestra "objetividad". Pero eliminar en absoluto la voluntad, dejar en suspenso la totalidad de los afectos, suponiendo que pudiéramos hacerlo: øcómo?, øes que no significaría eso castrar el intelecto?..." ${ }^{14}$. Dicho de otro modo, bajo la máscara de la objetividad, los propios valores son valoraciones $^{15}$.

A partir de este punto de partida (la crítica de los valores supremos y la determinación de su no-neutralidad), la perspectiva genealógica se despliega como mirada crítica de la tradición filosófica desarrollada en Occidente desde Platón ${ }^{16}$. Aunque, como señaló Deleuze, se trate de una "crítica total", nos centraremos aquí en la visión nietzscheana de la historia, auténtico arco sobre el que se apoya la flecha que el filósofo alemán dirige al corazón de la metafísica ${ }^{17}$. En este sentido, Michel Foucault señala al

13 CARR, EDWARD HALLET (1961), ¿Qué es la historia?, Ariel, Barcelona, 1993, p. 51.

14 NiETZSCHE, FRIEDRICH (1887), La genealogia de la moral. Un escrito polémico, Alianza Editorial, Madrid, 1995, p. 139.

15 Para Nietzsche, «son los valores los que suponen valoraciones, "puntos de vista de apreciación», de los que deriva su valor intrínseco", en DELEUZE, GILLES (1967), Nietzsche y la filosofia, Anagrama, Barcelona, 1971, p. 8.

16 Coincidimos con Juan Luis Vermal cuando señala que la crítica nietzscheana de la metafísica nose refiere tanto ana cierta parte o disciplina de la filosofía, cuanto a la totalidad del pensamiento occidental. [VERMAL, JUAN LUIS (1987), La critica de la metafisica en Nietzsche, Anthropos, Barcelona, pp. 15-20.]

17 Con respecto a la concepción nietzscheana de la Historia, Juan Luis Vermal considera que pueden hablarse de tres períodos distintos. En primer lugar, la concepción ahistórica de la II Intempestiva. Allí, Nietzsche establece la necesidad de pensar el pasado en función de la vida (necesidad de lo histórico desde la primacía de lo ahistórico). Una segunda etapa, que se inicia en 1878 con la publicación de Humano, demasiado humano, que el propio Nietzsche denomina "filosofía histórica" en el primer aforismo de la versión original de dicho libro (significativamente, en la redacción de 1888, Nietzsche habla de "filosofía del devenir"). Lo que caracteriza este segundo momento es que Nietzsche utiliza la historia para destruir aquellas construcciones 
menos tres niveles de genealogía posibles ${ }^{18}$ : una crítica del fundamento metafísico de la historia, una crítica del origen como el lugar de la perfección y de la esencia de las cosas y una pregunta por el valor de la verdad y de lo verdadero. Sin embargo, y esto es importante, no cabe comprender cada uno de estos espacios por separado, sino integrados en el marco de una perspectiva global. Las tres esferas están interrelacionadas, se solapan, se yuxtaponen, se mezclan y se acoplan. Las tres convergen en un punto: la mirada nietzscheana.

\subsection{La genealogía como crítica del fundamento metafisico de la historia}

$\mathrm{Si}$, como hemos señalado, el proyecto genealógico pretende derrumbar las falsas identidades metafísicas mostrando la futilidad de su origen, es evidente la necesidad de un movimiento complementario en sentido inverso: liberar a la historia de su "fidelidad a la obediencia metafísica» ${ }^{19}$. En este sentido, la crítica del fundamento metafísico de la historia es triple:

que impiden el surgimiento de lo real. Si lo característico de la metafísica es interpretar la realidad a través de dualidades (verdadero/aparente, movimiento/reposo, etc.), la ufilosofía histórica» diluye dichas oposiciones mostrando como "también los colores más hermosos están compuestos de materias viles, incluso despreciadas" (NIETZSCHE, FrIEDRICH (1878), Humano, demasiado humano, Edaf, Madrid, 1990, p. 42). De esta manera, la "filosoffa histórican traza los modos de formación de las identidades ideales dominantes. La historia acomete la tarea de desenmascarar a la metafísica y el "sentido histórico" consiste en comprender las diferentes posibilidades históricas como sistemas determinados y representantes de diferentes culturas, es decir, necesarios pero cambiantes. Por tanto, la Historia se convierte en la disciplina que debe mostrar el bajo origen de los conceptos que componen el armazón de la metafisica. Por último, un momento final o ufilosofia del devenir", donde se establece la necesidad de considerar el pasado sustrayéndolo a la totalidad de sentido que le da significación. Esta idea surge en conexión con la del eterno retorno, entendido este como la solución nietzscheana para una presencia del pasado liberada de la tiranía del origen y del sentido. Aunque la interpretación de Vernal me parece totalmente acertada, quisiera realizar un pequeño apunte. Como el propio autor sugiere en algunas páginas de su libro, no creo que se trate tanto de tres momentos cuanto de tres dimensiones de la filosofía nietzscheana de la Historia. Un ejemplo; la dimensión definida por la «filosofía histórican (que corresponde, grosso modo, a lo que nosotros denominamos genealogía) está plenamente presente en obras de la etapa final (claro ejemplo es La Genealogia de la Moral).

18 FouCAUlt, Michel (1971), Nietzsche, la Genealogia, la Historia, Pre-Textos, Valencia, 1992.

19 Idem, p. 51. 
- La historia tradicional introduce un punto de vista suprahistórico ${ }^{20}$. Es decir, se apoya en un elemento situado "fuera del tiempo", en una objetividad absoluta que pretende ordenar el discurso histórico desde el concepto de verdad. Desde la atalaya de "lo objetivo", la historia es contemplada como aquella totalidad que permite explicar de dónde venimos y a dónde vamos.

- La "historia de los historiadores" describe el devenir histórico de acuerdo con relaciones de causa-efecto; relaciones basadas en la descripción de cadenas causales que establecen vínculos entre «la irrupción del acontecimiento y la necesidad continua» ${ }^{21}$. De este modo, los hechos se insertan en una continuidad teleológica (caso de la tradición cristiana) o racionalista (caso del positivismo) que introduce un factor explicativo de clara inspiración metafísica. $\mathrm{La}$ historia se convierte en un proceso necesario, donde todos los acontecimientos adoptan la única forma posible y quedan ligados (o disueltos, que diría Foucault) en un continuum que, reconciliando al hombre con su pasado, justifica su presente.

- Como la metafísica, la historia tradicional gusta de contemplar las alturas y las lejanías. Todo es en ella una mirada hacia las individualidades más destacadas, hacia los ideales más puros, hacia las épocas más importantes.

Frente a esto, Nietzsche afirma que «la historia tiene más que hacer que servir a la filosofía y narrar el nacimiento necesario de la verdad y del valor» ${ }^{22}$. Es necesaria una nueva historia que rompa las cadenas que la aprisionan:

- La historia debe dejar de apoyarse sobre esa verdad eterna y exterior que permite concebir el proceso histórico como totalidad: “En Nietzsche, esta totalidad es destruida [...] su manera de concebir la historia es, por así decirlo, fragmentaria» ${ }^{23}$. El sentido histórico debe dividir lo que se creía homogéneo,

20 "Llamo, por otro lado, "lo suprahistórico" a los poderes que desvían la mirada de lo que meramente deviene, dirigiéndola a lo que da a la existencia el carácter de lo eterno e idénticon, en NiETZSCHE, FRIEDRICH (1873), Sobre la utilidad y el perjuicio de la bistoria para la vida. II Intempestiva, Biblioteca Nueva, Madrid, 1999, p. 136.

21 Foucault, Michel (1971), Nietzsche, la Genealogia, la Historia, Pre-Textos, Valencia, 1992, p. 48.

22 Idem, p. 53.

23 "Chez Nietzsche, cette totalité est déchirée [...], la manière dont il pense l'bistoire est-ella pour ainsi dire fragmentaire», en JASPERS, KARL (1950), Nietzsche. Introduction à sa philosophie, Gallimard, Paris, p. 235. 
debe trocear lo que juzgábamos continuo, debe mostrar las fisuras de aquello que pensábamos perfecto.

- La Historia no puede explicarse desde relaciones causa-efecto que disuelvan los acontecimientos en el magma de una continuidad necesaria. Los hechos han acontecido de una de las muchas formas posibles (no de la única manera posible) y su explicación no hay que buscarla en la mecánica sino en el azar: "la historia entera de una "cosa", de un órgano, de un uso, puede ser así una ininterrumpida cadena indicativa de interpretaciones y reajustes siempre nuevos, cuyas causas no tienen siquiera necesidad de estar relacionadas entre sí, antes bien a veces se suceden y se relevan de un modo meramente casual» ${ }^{24}$.

- La Historia debe olvidar las grandes alturas para concentrar su mirada en lo pequeño, alejándose de esa profundidad aparente e ideal que suponíamos en un inicio y que se demuestra falsa. Para ello, al igual que Zarathustra, es necesario "comenzar el descenso".

En definitiva, la genealogía pretende "localizar la singularidad de los acontecimientos, fuera de toda finalidad monótona, atisbarlos donde menos se les espera, y en lo que pasa por no tener historia- los sentimientos, el amor, la conciencia, los instintos-; captar su retorno, no para trazar la curva lenta de una evolución, sino para reconocer las diferentes escenas en las que han representado papeles diferentes, definir incluso el punto de su ausencia, el momento en el que no han sucedido" ${ }^{25}$. La genealogía se opone a dar un sentido de evolución a la historia y por eso elimina lo trascendente y lo teleológico. Frente a historia tradicional que, apoyada en la metafísica, pretendía encontrar la esencia de los acontecimientos en algún lugar anterior al tiempo, al espacio y al mundo, la genealogía descubre que dicha esencia no existe o que ha sido construida a partir de elementos ajenos al propio acontecimiento.

La vinculación que se establece entre metafísica e historia no sólo define la naturaleza de lo que Nietzsche denomina la "historia de los historiadores", sino que determina su escritura. Atrapada en dicha dependencia, la historia ha

24 NIETZSCHE, FRIEDRICH (1887), La genealogia de la moral. Un escrito polémico, Alianza Editorial, Madrid, 1995, p. 88.

25 FouCault, MrChel (1971), Nietzsche, la genealogia, la historia, Pre-Textos, Valencia, 1992, p. 12. 
adoptado la forma de descripciones lineales basadas en la búsqueda del principio activo que pueda explicar la evolución. En este sentido, Nietzsche realiza una crítica que Foucault desarrollará más tarde: Las descripciones lineales colocan el punto de vista del presente en el comienzo del acontecimiento histórico ${ }^{26}$. De este modo, la genealogía se despliega como crítica y acción, denunciando por un lado a los ingenuos historiadores que «denominan «objetividad» justamente a medir las opiniones y las acciones del pasado desde las opiniones comunes del momento presente [...] mientras, por el contrario, llaman «subjetivan a cualquier historiografía que no tome como canónicas aquellas opiniones comunes y normales» ${ }^{27}$ y, por otro lado, «emplazándonos a problematizar esta necesidad presente que se legitima en tanto que tal poniéndose como posibilidad intemporal ahora finalmente revelada ${ }^{28}$.

Un ejemplo concreto. En la segunda disertación de la Genealogía de la moral, Nietzsche se pregunta por el origen del castigo. Ante tal cuestión, un historiador tradicional hubiera procedido de la siguiente manera: al descubrir que el castigo tiene una meta determinada (por ejemplo, la venganza o la disuasión), hubiera situado dicha meta en el origen, concediéndola el rango de causa prima. De este modo, su conclusión hubiera sido que el castigo nació bien como venganza, bien por su capacidad de disuasión. Sin embargo, Nietzsche parte de una premisa distinta: la causa original de algo y su signifi-

26 Foucault retoma la idea nietzscheana de la negación del presente como instancia valorativa y como lugar de la objetividad: «Creo que estamos ante una de las formas, quizá haya que decir una de las costumbres más nocivas del pensamiento conemporáneo, diría incluso del pensamiento moderno o, en todo caso, del pensamiento posthegeliano: el análisis del momento presente como si éste fuera precisamente en la historia el momento de la ruptura o el momento del balance, o del cumplimiento, o el de la aurora que retorna. La solemnidad con que toda persona que mantiene un discurso filosófico refleja su propio momento me parece un estigma. Digo esto porque lo he hecho yo mismo [...] Creo que debemos tener la modestia de decirnos que, por una parte, el momento en el que vivimos no es el momento único, fundamental o que irrumpe en la historia [...]. No concediéndonos la facilidad algo dramática o teatral de afirmar que en este momento en el que nos encontramos es, en lo más profundo de la noche, el de la perdición mayor, o en el despuntar del día, aquel en el que el sol triunfa, etc. No, es un día como los otros, o más bien es un día que nunca es igual completamente a los demás.» FOUCAULT, MiCHEL (1983), "Estructuralismo y postestructuralismo", Estética, ética y hermenéutica. Obras esenciales. Volumen III, Paidós, Barcelona, 1999, p. 325.

27 NieTzSCHE, FruedruCH (1873), Sobre la utilidad y el perjuicio de la historia para la vida. II Intempestiva, Biblioteca Nueva, Madrid, 1999, pp. 88-89.

28 Morey, Miguel (1994), «La genealogía como estilo filosófico», Nietzsche. Nuevos horizontes interpretativos; Foucault. La arqueología del poder y de las resistencias. (Ciclos de Conferencias sobre Michel Foucault y Nietzsche, La Coruña, abril 93/abril 94), Fundación Paideia, La Coruña, p. 67. 
cado final son dos cosas distintas, dos momentos separados por la propia historia (esa historia anulada por aquellos que consideran que en el pasado las cosas ocurrieron como en el presente). Por lo tanto, la conclusión a la que llega el genealogista es, necesariamente, diferente: "el concepto de "pena" no presenta ya de hecho un sentido único, sino toda una síntesis de "sentidos": la anterior historia de la pena en general, la historia de su utilización para las más distintas finalidades, acaba por cristalizar en una especie de unidad que es dificil de disolver, dificil de analizar, y que, subrayémoslo, resulta del todo indefinible»" ${ }^{29}$.

Después de haber esbozado las grandes líneas de la crítica nietzscheana del fundamento metafísico de la historia, ha llegado el momento de plantearse una cuestión fundamental: ¿Por qué la historia debe desligarse de la metafísica? La respuesta que trataré de resumir en las siguientes líneas es la siguiente: Porque lo histórico tiene su origen en lo ahistórico. La introducción de dicha dualidad está relacionada con la visión nietzscheana de la naturaleza humana. Según la misma, el ser humano posee dos facultades contradictorias: el olvido ${ }^{30}$ y la memoria. El olvido es la "capacidad de poder sentir de manera no histórica, abstrayéndose de toda duración»" ${ }^{31}$. Gracias a él, nos acercamos a la felicidad inconsciente de los animales y nos situamos del lado de la vida. La memoria, obligándonos a cargar con la cadena de recuerdos del pasado, es necesaria porque habilita la historia, la reflexión, la síntesis. Se establece de este modo una tensión entre ambas facultades. Esa tensión queda expresada en los siguientes términos: "lo ahistorico y lo histórico son en igual medida nece-

29 NieTZSCHE, Friedrich (1887), La genealogia de la moral. Un escrito polémico, Alianza Editorial, Madrid, 1995, p. 91.

30 El olvido es un concepto fundamental en Nietzsche. Por un lado, es el mecanismo que permite la consolidación de un conocimiento verdadero: «Solamente mediante el olvido puede el hombre alguna vez llegar a imaginarse que está en la posesión de la verdad." [NIETzSCHE, FRIEDRICH (escrito en 1873 y publicado en 1902), Sobre verdad y mentira en sentido extramoral, Tecnos, Madrid, 1994, p. 21). Por otro lado, el olvido se refiere a la capacidad de poder sentir de manera no histórica, de abstraerse de la duración. Es la inconsciencia y en él se genera la vida. Con respecto a este segundo sentido, Giorgio Colli ha señalado las debilidades de la argumentación nietzscheana. Para Colli, toda conciencia se funda en el recuerdo y las acciones de los hombres aparecen en el escenario de la historia, por tanto, es falso que dichas acciones carezcan de conciencia mientras se desarrollan. [COLLI, GloRgio (1980), Introducción a Nietzsche, PreTextos, Valencia, 2000, pp. 51-54.]

31 NIETZSCHE, FRIEDRICH (1873), Sobre la utilidad y el perjuicio de la historia para la vida. II Intempestiva, Biblioteca Nueva, Madrid, 1999, p. 42. 
sarios para la salud de un individuo, de un pueblo o de una cultura" ${ }^{32}$. Pero, ¿cómo se regula dicha relación? A través de lo que Nietzsche denomina fuerza plástica, fuerza «que determina cuánto historicismo puede ser tolerado sin convertirse en peligroso" ${ }^{33}$. Ella nos indica lo que es importante olvidar y lo que es necesario recordar.

Sea como fuere, y aunque Nietzsche señale la necesidad de ambos elementos, lo cierto es que sitúa lo ahistórico en el inicio de lo histórico. Cualquier acontecimiento histórico se genera en la atmósfera de lo abistórico debido a que, en ese conflicto permanente entre conocimiento y vida, «nadie ha de dudar: la vida es el poder máximo, dominante, porque un conocimiento que destruye la vida acabaría consigo mismo" ${ }^{34}$. La historia se genera desde los valores de lo ahistórico, desde esa atmósfera envolvente que no es otra cosa que una metáfora de la vida. En este sentido, la capacidad de sentir de manera no-histórica es originaria y anterior a la histórica. Ante esta realidad desvelada por el genealogista, la Historia tradicional queda desnuda e incapaz de responder a cuestiones capitales: ¿̨por qué esa intromisión de lo metafísico en lo histórico?; ¿por qué esa necesidad de buscar un punto de apoyo más allá del tiempo?; ¿por qué buscar lo trascendente en algo que tiene su origen en lo intranscendente?

2.2. La genealogía y la crítica del origen como el lugar de la esencia

La utilización del término genealogía está en relación con la ya mencionada preocupación de Nietzsche por el origen de aquellos elementos (la moral, la razón, etc.) que han definido el pensamiento occidental. Para analizar la crítica nietzscheana, me ceñiré a la lectura que realiza Michel Foucault en su ensayo sobre la genealogía.

32 Idem, p. 45. E. Trias señala la importancia de esta idea en Nietzsche: "El experimento filosófico se produce en la tensa relación, conflicto o lucha, entre conocimiento y vidas en Trias, EugenIo (1987), "Introducción", La critica de la metafisica en Nietzsche, Anthropos, Barcelona, p. 9.

33 "Qui determine combien d'historicisme peut être toléré sans devenir dangereux», en JASPERS, KaRL (1950), Nietzsche. Introduction à sa philosophie, Gallimard, Paris, p. 243.

34 NIETZSCHE, FRIEDRICH (1873), Sobre la utilidad y el perjuicio de la historia para la vida. II Intempestiva, Biblioteca Nueva, Madrid, 1999, p. 136. 
En una de las primeras frases de dicho ensayo podemos leer que la genealogía "se opone a la búsqueda del "origen" " 35 , sentencia que parece entrar en abierta contradicción con la etimología del concepto. Sin embargo, la disección foucaultiana establece una doble línea analítica que permite superar dicha paradoja:

- La genealogía se opone a la búsqueda del origen como Ursprung.

- La genealogía busca los comienzos como Herkunft y como Entstehung.

\section{2.a. La genealogía se opone a la búsqueda del origen como Ursprung}

Foucault distingue dos usos de la palabra Ursprung (origen) en Nietzsche. En el primer caso, el filósofo alemán lo utiliza de manera indistinta junto con otros sinónimos como Herkunft o Entstehung. El segundo uso establece una oposición entre Ursprung y Herkfunt (procedencia) o Erfindung (invención) ${ }^{36}$. Este segundo caso es utilizado por Foucault para afirmar que la genealogía no es la búsqueda del origen si entendemos por este último:

- A. El origen como la esencia de las cosas.

- B. El origen como el estado de perfección de las cosas.

- C. El origen como lugar de la verdad.

35 Foucault, Michel (1971), Nietzsche, la historia, Pre-Textos, Valencia, 1992, p. 13.

36 En "La verdad y las formas jurídicas", Foucault analiza el sentido de la oposición Ursprung-Erfindung. De acuerdo con Foucault, Nietzsche afirma que los hombres inventaron (de Erfindung, invención) el conocimiento, y utiliza ese término oponiéndolo al de origen (Ursprung). En este sentido, se opone a Schopenhauer de quien dice cometió el error de buscar el origen de la religión en un sentimiento metafísico supuestamente universal y presente en todos los hombres, sentimiento que contendría anticipadamente el núcleo de cualquier religión (Foucault se refiere al aforismo trescientos cincuenta y tres de la Gaya Ciencia, titulado «El origen de las religiones"). Para Nietzsche la religión no tiene origen (Ursprung), sino que fue inventada a partir de una serie de acontecimientos que la hicieron posible. [FOUCAULT, MiCHEL (1974), "La verdad y las formas jurídicas", Estrategias de poder. Obras esenciales. Volumen II, Paidós, Barcelona, 1999, pp. 169-281.] La idea del conocimiento como invención aparece en varias ocasiones a lo largo de la obra de Nietzsche, véase por ejemplo, el primer párrafo de Sobre verdad y mentira en sentido extramoral. 
Los historiadores anteriores a Nietzsche habían buscado el origen de las cosas esperando encontrar allí su esencia. Esta esencia se situaba siempre en el comienzo, lugar donde el acontecimiento se dibujaban en estado puro (toda vez eliminadas las connotaciones externas y accidentales incorporadas por el devenir histórico). El origen era concebido, pues, como el lugar de la objetividad y de la verdad.

Sin embargo, el genealogista descubre "que detrás de la cosas hay otra "cosa bien distinta": no su secreto esencial y sin fecha, sino el secreto de que no tienen esencia, o de que su esencia fue construida pieza a pieza a partir de figuras que le eran extrañas. ¿La razón? Que ha nacido de una forma del todo "razonable": el azar" ${ }^{37}$. El problema, por tanto, se plantea en términos no de búsqueda del "origen" ("la historia genealógica nos enseña a reirnos de las solemnidades del origen") ${ }^{38}$ sino en la indagación de aquello que hay detrás de las cosas; es decir, en la exploración del sentido.

La pregunta que se impone es evidente: ¿qué hay detrás de las cosas? La respuesta: los intereses (fuerzas) de aquellos que intentan apropiárselas. De este modo, 'nunca encontraremos el sentido de algo (fenómeno humano, biológico o incluso físico), si no sabemos cuál es la fuerza que se apropia la cosa, que la explota, que se apodera de ella o se expresa a través de ella" ${ }^{39}$. Los fenómenos son signos que podemos interpretar descubriendo con qué fuerzas se relacionan, de tal manera que un mismo fenómeno cambia de sentido dependiendo de la fuerza que trate de dominarlo. Por eso las cosas no tienen un sentido único, por eso las cosas no tienen una única esencia. La genealogía pone este hecho en evidencia y define la historia como el estudio de la variación de las interpretaciones de los fenómenos. De este modo, una genealogía de la moral será aquella que describa la cadena interrumpida de interpretaciones elaboradas al respecto. El sentido de las cosas no existe más que como pluralidad, de manera que » no hay ningún acontecimiento, ningún fenómeno, palabra ni pensamiento cuyo sentido no sea múltiplen ${ }^{40}$.

37 Foucault, Michel (1971), Nietzsche, la Genealogia, la Historia, Pre-Textos, Valencia, 1992, p. 19.

38 QUeSADA, JUlio (1994), "Nietzsche: risa, genealogía, carnaval. El teatro del "yo", Nietzsche. Nuevos horizontes interpretativos; Foucault. La arqueologta del poder y de las resistencias. (Ciclos de Conferencias sobre Michel Foucault y Nietzsche, La Coruña, abril 93/abril 94), Fundación Paideia, La Coruña, p. 63.

39 DeleuZE, Gilles (1967), Nietzsche y la filosofia, Anagrama, Barcelona, 1971, p. 10.

40 Idem, pág. 11. 
Al mismo tiempo, la genealogía se opone a la búsqueda del origen entendido éste como el estado de perfección de las cosas. Esta concepción se encuentra, por ejemplo, en Platón o en el pensamiento judeo/cristiano. En la Biblia encontramos numerosas veces la imagen de un origen noble, símbolo de pureza, previo a la caída (léanse, por ejemplo, la expulsión de Adán y Eva del Paraíso o Babel). Es la idea de que uel origen siempre está antes que la caída, antes que el cuerpo, antes que el mundo y el tiempo, está del lado de los dioses, y al narrarlo siempre se canta una teogonía" ${ }^{41}$. La genealogía sin embargo, considera que "con la intelección del origen, aumenta la insignificancia de ese origen", ya que todo comienzo es intranscendente, innecesario, azaroso. Sobre el origen divino, "este camino nos está hoy vedado, pues en su entrada hay un mono, con otros animales de aspecto no menos espantoso" 43.

Por último, la genealogía se opone al origen como lugar de la verdad. La crítica genealógica del origen, como en los dos primeros casos, vuelve a cargar contra la intromisión de lo metafísico en lo histórico. Si analizamos sus tres vértices (negación del origen como esencia, como perfección y como verdad) vemos tres variaciones de una misma idea: «la genealogía no viene a fundamentar un origen" 44 .

2.2.b. La genealogía busca los comienzos como Herkunft y como Entstehung

Normalmente ambos términos son traducidos por "origen" y, ciertamente, en muchas ocasiones Nietzsche los utiliza de manera indistinta. Sin embargo, en opinión de Foucault, "señalan mejor que Ursprung el objeto propio de la genealogía" ${ }^{45}$.

41 Foucault, MiChel (1971), Nietzsche, la Genealogia, la Historia, Pre-Textos, Valencia, 1992 , p. 20.

42 NiETZSCHE, FriedriCH (1881), Aurora, LIBSA, Madrid, 2000, p. 41.

43 Idem, p. 43.

44 QUESADA, JUlio (1994), "Nietzsche: risa, genealogía, carnaval. El teatro del "yo"", Nietzsche. Nuevos horizontes interpretativos; Foucault. La arqueologia del poder y de las resistencias. (Ciclos de Conferencias sobre Michel Foucault y Nietzsche, La Coruña, abril 93/abril 94), Fundación Paideia, La Coruña, p. 63.

45 Foucault, Michel (1971), Nietzsche, la Genealogia, la Historia, Pre-Textos, Valencia, 1992 , p. 24 


\section{Herkunft (procedencia)}

Continuando con Foucault, podemos traducir Herkunft como el tronco, como la procedencia: "Es la vieja pertenencia a un grupo, el de la sangre, el de la tradición, el que se orea entre los de una misma nobleza o una misma bajeza" ${ }^{46}$. Se trata de una mirada profunda, una introspección que revela las pequeñas marcas sutiles que se entrecruzan en el individuo. Esas huellas, casi borradas por el paso del tiempo, permanecen escritas en el cuerpo, lugar de la procedencia: «El cuerpo, y todo lo que atañe al cuerpo: la alimentación, el clima, el suelo, es el lugar de la Herkunft: sobre el cuerpo encontramos el estigma los acontecimientos pasados» ${ }^{47}$. En el cuerpo quedan grabados errores y aciertos de las generaciones pasadas, una historia subterránea que el genealogista se propone sacar a la luz ${ }^{48}$. En ningún caso el análisis del cuerpo como lugar de la procedencia pretende dotar de una identidad al Yo. Al contrario: «El análisis de la procedencia permite disociar el Yo y de hacer pulular, en los lugares y sitios de su síntesis vacía, mil acontecimientos ahora perdidos» ${ }^{49}$.

\section{Entstehung (emergencia)}

Definimos la Entstehung como la emergencia ${ }^{50}$, como el punto de surgimiento, como la génesis ${ }^{51}$. Para Nietzsche, el origen debe buscarse más allá del simple etnocentrismo. ¿Dónde? En la emergencia. Si, como ya habíamos indicado, la historia de una cosa es la historia de las fuerzas que han tratado de apropiársela, entonces «la emergencia se produce siempre en un cierto estado de las fuerzas. El análisis de la Entstehung debe mostrar el juego, la manera en que luchan unas contra las otras, o el combate que llevan a cabo frente a cir-

46 Idem, p. 25.

47 Idem, pp. 31-32.

48 Un ejemplo para comprender este lenguaje metafórico es el aforismo trescientos cuarenta y ocho de La Gaya Ciencia.

49 FouCAult, MiCHEL (1971), Nietzsche, la Genealogia, la Historia, Pre-Textos, Valencia, 1992, pp. 26028.

so Idem, p. 33.

51 MOREY, MigUEL (1994), "La genealogía como estilo filosóficon, Niezzsche, Nuevos horizontes interpretativos; Foucault. La arqueologia del poder y de las resistencias. (Ciclos de Conferencias sobre Michel Foucault y Nietzsche, La Coruña, abril 93/abril 94), Fundación Paideia, La Coruña, p. 68. 
cunstancias adversas" ${ }^{52}$. Si la procedencia se inscribe en el cuerpo, la emergencia lo hace en el espacio. La emergencia analiza la lucha de las fuerzas por apropiarse de las cosas ("Cualquier fuerza es apropiación, dominación, explotación de una porción de realidad») ${ }^{53}$, pero no lo hace desde un punto de vista dialéctico. No se trata, como en Hegel, de una evolución de las cosas a través de sus contradicciones; no hablamos aquí de la acción de una fuerza y la reacción de otra. Las fuerzas no se suceden en el tiempo, sino que se entrecruzan, se mezclan, se confunden sin llegar a enlazarse. La emergencia nombra el espacio donde se distribuyen dichas fuerzas, el "campo de batalla" donde buscan apoderarse de esa "cantidad de realidad" que menciona Deleuze. Pero, Foucault nos advierte, no pensemos en un lugar cerrado; sino en un espacio abierto, en el escenario gigantesco que resulta de la distancia entre los adversarios. La emergencia define una distancia, un no-lugar.

Por tanto, la formación de los conceptos morales se produce a través de la lucha entre fuerzas que pretenden la apropiación de una cierta realidad. El escenario que da lugar al inicio del conflicto lo denominamos emergencia y las huellas que la lucha deja sobre el cuerpo, sobre la cultura, sobre el paisaje, las relacionamos con la procedencia. Podemos rastrear dichas marcas a través del estudio del lenguaje ya que el origen del lenguaje no es sino una «exteriorización de poder de los que dominan: dicen "esto es esto y aquello", imprimen a cada cosa y a cada acontecimiento el sello de un sonido y con esto se lo apropian» ${ }^{54}$.

\subsection{La genealogía, una pregunta por el valor de la verdad}

El problema de la verdad está absolutamente intrincado con la crítica del fundamento metafísico de la historia. Si me he decidido a abordarlo por sepa-

52 Foucault, Michel (1971), Nietzsche, la Genealogia, la Historia, Pre-Textos, Valencia, 1992, p. 34.

53 DeleUZE, GILles (1967), Nietzsche y la filosofia, Anagrama, Barcelona, 1971, p. 10.

54 NiETSCHE, FRIEDRICH (1887), La genealogia de la moral. Un escrito polémico, Alianza Editorial, Madrid, 1995, p. 32. Aunque la idea del lenguaje como marcador de poder está presente en varios momentos de la obra de Nietzsche, un texto decisivo en este sentido es Sobre verdad y mentira en sentido extramoral, donde la crítica de la verdad como correspondencia se relaciona con la idea de que "el poder legislativo del lenguaje proporciona también las primeras leyes de verdad" en NIETZSCHE, FRIEDRICH (escrito en 1873 y publicado en 1902), Sobre verdad y mentira en sentido extramoral, Tecnos, Madrid, 1994, p. 20. 
rado ha sido más por tratar de sistematizar mi propuesta, que porque existan razones para hacerlo.

En su lucha contra la trascendencia y el finalismo de la vieja filosofía, Nietzsche plantea un problema esencial: el valor de la verdad y de lo verdadero. De acuerdo con el filósofo de Röcken, analizar esta cuestión es pasar revista a la historia de un prejuicio que envenena no sólo el ámbito de lo religioso, sino también la filosofía y la historia: la idea de la superioridad de lo verdadero frente a lo falso (como señala Karl Jaspers: "El curso de la historia nos muestra, según Nietzsche, la dominación del hombre por eficaces errores de orden metafísico, religioso, moral") ${ }^{55}$. Nietzsche es el primero que se cuestiona la validez de esa idea, inaugurando de este modo la filosofía moderna ${ }^{56}$. Aquellos que defienden la verdad, defienden "una tesis adoptada de antemano, una ocurrencia, una "inspiración" [...] todos ellos son abogados que no quieren llamarse así, y en la mayoría de los casos son incluso pícaros patrocinadores de sus prejuicios a los que bautizan con el nombre de "verdades" 57 . De este modo, la genealogía reclama, a través de una crítica del concepto de verdad como idea rectora del conocimiento (entendida como objetividad absoluta y excluyente), una filosofía y una historia intrascendentes (puesto que la trascendencia iba ligada a lo verdadero) y no-teleológicas (puesto que la verdad ha dejado de ser aspiración suprema y final de la filosofía). La propuesta es clara: «La objetividad en el historiador es la inversión de las relaciones entre el querer y el saber y, a la vez, la creencia necesaria en la Providencia, en las causas

55 "Le cours de l'histoire nous montre selon Nietzsche la domination de l'bomme par les afficaces erreurs d'ordre métaphysique, religieux, moral." en JASPERS, KARL (1950), Nietzsche. Introduction à sa philosphie, Gallimard, Paris, p. 238.

56 La pregunta por el valor de la verdad introduce, en opinión de Deleuze, una ruptura en la historia de la filosofía: «En este sentido Kant es el último de los filósofos clásicos: Nunca pone en cuestión el valor de la verdad, ni las razones de nuestra sumisión a lo verdadero» en DELEUZE, Gilles (1971), Nietzsche y la filosofia, Anagrama, Barcelona, p. 134. Ciertamente, en algunas ocasiones el propio Nietzsche es consciente de esa distancia que le separa de Kant: "Ha llegado por fin la hora de sustituir la pregunta kantiana "¿cómo son posibles los juicios sintéticos a priori?", por una pregunta distinta “¿Por qué es necesaria la creencia en tales juicios" "n NiETZSCHE, FRIEDRICH (1886), Más allá del bien y del mal, Alianza Editorial, Madrid, 1986, p. 23. Una buena síntesis del diálogo de Nietzsche y Kant, entendido no tanto en clave de ruptura como de revisión, la encontramos en Reboul, Oliver (1974), Nietzsche, critique de Kant, Presses Universitaires de France, Paris. (Hay traducción castellana: Nietzsche, critico de Kant, Anthropos, Barcelona, 1993.)

57 NiETzSCHE, FrIKEDRICH (1886), Más allá del bien y del mal, Alianza Editorial, Madrid, 1986 , p. 25. 
finales y en la teleologían 58 . Frente a esta creencia, los nuevos filósofos, esos del peligroso "quizá» ${ }^{59}$, tienen que abrir nuevos caminos sabiendo que no tienen la verdad. Los nuevos pensadores tienen que ser tentadores ${ }^{60}$.

Es imposible siquiera repasar aquí las implicaciones más importantes de la crítica de Nietzsche al concepto tradicional de verdad. Por esta razón prefiero, de la mano de Foucault, limitarme a valorar la crítica nietzscheana de la objetividad y del historicismo. A este respecto, es posible entender esta crítica como una reacción contra el positivismo de principios de siglo. Según Nietzsche, la historia o bien «su pretensión más noble se reduce hoy a ser espejo: rechaza toda teleología; ya no quiere "demostrar" nada: desdeña el desempeñar el papel de juez, y tiene en ello su buen gusto, ni afirma, ni niega, hace constar, "describe"... Todo esto es ascético en alto grado; pero a la vez es, en un más alto grado todavía, nihilista" ${ }^{61}$; o bien "monopoliza totalmente la loa de la contemplación»" ${ }^{62}$.

Nietzsche comienza su crítica en los mismos términos que los que utiliza en su evaluación de «la voluntad de verdad»: «iEs cierto que esta objetividad tiene como origen una acrecentada necesidad y exigencia de justicia? ¿ $\mathrm{O}$ acaso se suscita como efecto de otras causas totalmente distintas, produciendo la apariencia de que la objetividad es la única causa de este efecto?"» ${ }^{63}$. En otras palabras, Nietzsche plantea el problema del "valor de la objetividad». Su respuesta es concluyente: la objetividad no es más que una apariencia, una máscara que en realidad encubre otros intereses.

La denuncia se centra en el "principio etnocéntrico" utilizado por el historicismo y en la historia practicada por "esas gentes totalmente irreflexivas que

58 FOUCAUlt, MiCHEL (1971), Nietesche, la Genealogia, la Historia, Pre-Textos, Valencia, 1992 , p. 59.

59 NiETzSCHE, Friedrich (1886), Más allá del bien y del mal, Alianza Editorial, Madrid, 1986, p. 23.

60 Según Heidegger, "los nuevos pensadores tienen que ser tentadores, es decir, cuestionando tienen que tentar y poner a prueba el ente mismo respecto de su ser y de su verdadn en HeIDDEGER, MARTIN (1961), Nietzsche, Destino, Barcelona, 2000, p. 37.

61 NiETZSCHE, FRIEDRICH (1887), La genealogia de la moral. Un escrito polémico, Alianza Editorial, Madrid, 1995, p. 179.

62 Idem, p. 180.

63 NIETZSCHE, FRIEDRICH (1873), Sobre la utilidad y el perjuicio de la historia para la vida. II Intempestiva, Biblioteca Nueva, Madrid, 1999, p. 84. 
escriben bajo el nombre de historiadores con la ingenua creencia de que justamente su tiempo posee la razón en todas las opiniones corrientes y que escribir conforme a dicho tiempo significa lo mismo que ser justo, una creencia por otro lado en la que vive cualquier religión" " ${ }^{64}$. De nuevo, el problema se produce al considerar el punto de vista del presente como el único válido. El historicismo plantea la historia como una totalidad donde los elementos se distribuyen de acuerdo a un plan unitario. En su examen, el genealogista descubre que esa búsqueda de la "objetividad" esconde en realidad algo mucho más bajo: una pretensión de justicia. El historicista «quiere la verdad, pero no sólo como conocimiento frío y sin consecuencias, sino como aquella jueza que ordena y castiga" ${ }^{65}$. Considera que la verdad está de su lado y que eso le habilita para juzgar el pasado desde su óptica; por eso, Nietzsche intuye que la "cuestión clave es desmantelar la instancia valorativa del presente, para así realizar un juicio (histórico) filosófico acerca del valor y del significado del conocimiento histórico "objetivo" para la praxis, para la acción" ${ }^{66}$. El objetivismo anula tanto al historiador como a la historia, y lo hace en un doble sentido:

- Al exigir al historiador que renuncie a su subjetividad, le suprime y le hace perder la perspectiva, llegando incluso, "al punto de suponer que precisamente a quien no le interesa en absoluto un momento del pasado es el más adecuado para describirlo. De este modo se comportan frecuentemente los filólogos con los griegos: éstos no les interesan en lo más mínimo, o, lo que es lo mismo, a esto se le llama "objetividad" " 67.

- Al considerar que todo vale lo mismo, el historicismo hace tabla rasa de la historia. Hay que conocerlo todo, no hay diferencias, tampoco jerarquías ni distinción de valor. La capacidad crítica se diluye en la obligatoriedad de la comprensión total. La posibilidad de una historia crítica se pierde de este modo «bajo la máscara d elo universal» ${ }^{68}$.

Sin embargo, y pese a dificultar la posibilidad de una historia crítica, la ilusión objetivista cumple una función importante: "Sólo un monstruo puede

\footnotetext{
64 Idem, p. 88 [el subrayado es mío].

65 Idem, p. 85.

66 Idem, p. 21.

67 Idem, p. 93.

68 FouCAULT, Michel (1971), Nietzsche, la Genealogia, la Historia, Pre-Textos, Valencia,
} 1992, p. 57. 
permitirse el lujo de ver las cosas tal y como son. Sin embargo, una colectividad subsiste en la medida que se crea ficciones, las sostiene y las consagra” ${ }^{69}$. Nietzsche elabora una teoría cognoscitiva que considera que el conocimiento cumple para el hombre la doble función de adaptación y dominio de la naturaleza ${ }^{70}$. El entendimiento tiende a crear mundos simbólicos que permiten satisfacer nuestras necesidades, asegurándonos un espacio donde permanecer a salvo. Para ello es necesario que lo simbólico, a través del autoengaño o de la aceptación inconsciente de la ficción, sea aceptado como convencional; es decir, que la verdad (que no es sino construcción) se convierta en una realidad aceptada por todos los miembros del grupo ${ }^{71}$. Habermas lo resume del siguiente modo: «El soterrado objetivismo que oculta que la subjetividad creadora de sentido es la que produce las condiciones de posible interpretación de aquello que tomamos como realidad, es condición de existencia de una especie que se conserva por virtud de la inteligencia. En cuanto es entrevista aquella ilusión, inmediatamente se desmorona también el correspondiente de verdad en sentido de un convenionalismo linguístico" ${ }^{72}$. Siguiendo con Habermas, podemos concluir que Nietzsche «sustituye la verdad de los enunciados por la fe subje-

69 "Seul un monstre peut se permettre le luxe de voir les choses teles quéelles sont. Mais une collectivité ne subsiste que dans la mesure où elle se crée des fictions, les entretient et s'y attache» en CIORAN, E. M. (1960), Histaire et utopie, Gallimard, Paris.

70 Un magnífico trabajo sobre la función del conocimiento en Nietzsche lo encontramos en VAiHINGer, HANS (1994), La voluntad de ilusión en Nietzsche, Tecnos, Madrid. (Publicado junto con Sobre verdad y mentira en sentido extramoral). De acuerdo con Vaihinger,, para Nietzsche existe una tensión entre el mundo del "cambiante y evanescente" devenir y el mundo del user" donde todo aparece redondo y completo. Este último es un mundo inventado, pero justificado e indispensable. La vida, como nuestra cultura y nuestro conocimiento, necesita ilusiones, es decir, falsedades consideradas verdades. Mientras no se consolide ese mundo imaginario, cuyo «error fundamental" es la creencia en la permanencia, no será posible el edificio del conocimiento.

71 En Sobre verdad y mentira en sentido extramoral, Nietzsche repite una idea que más tarde será clave en Foucault: el carácter convencional de la verdad. Para poder vivir en sociedad, el hombre necesita un "tratado de paz", un acuerdo que conlleva fijar aquello que la sociedad considera como verdadero. De este modo, se inventa una "designación de las cosas uniformemente válida y obligatoria» (20): la verdad se constituye como algo "útil", nacido del "compromiso que la sociedad establece para existir" (25). Más aún, en términos morales la verdad se relaciona conel "compromiso de mentir de acuerdo con una convención firme, mentir borreguilmente, de acuerdo con un estilo vinculante para todos" (25). ¿Qué es entonces la verdad? "las verdades son ilusiones de las que se han olvidado que lo son" (25). NIETZSCHE, FRIEDRICH (escrito en 1873 y publicado en 1902), Sobre verdad y mentira en sentido extramoral, Tecnos, Madrid, 1994.

72 HABERMAS, JURGEN (1968), "La crítica nihilista del conocimiento en Nietzsche», Sobre Nietzsche y otros ensayos, Madrid, Tecnos, 1982, pp. 46-47. 
tiva en la verdad de los enunciados" ${ }^{73}$, invalidando de este modo los juicios sintéticos a priori kantianos y definiendo el conocimiento verdadero como convención.

A partir de esta breve introducción a la teoría del conocimiento, ¿cómo es posible la creencia en la objetividad?; ¿tiene sentido hablar de "conocimiento posible, y por tanto, de juicios que puedan ser objetivamente verdaderos"? ${ }^{74}$; ¿es posible continuar con el historicismo y con la fórmula de Ranke Wie es eigentlich gewesen? La respuesta es no. En este sentido, el historicismo es una vía agotada.

\section{A modo de conclusión}

En este artículo me he propuesto esbozar una de las posibles definiciones del concepto de genealogía en Nietzsche. Dos han sido los hilos conductores (también limites) que he utilizado: la interpretación foucaultiana de dicho concepto y sus implicaciones par ala lectura/escritura de la historia. Quisiera finalizar ahora con algunas palabras sobre el carácter de este trabajo. En ningún caso he intentado proponer una metodología coherente y un cojunto de recetas desde las que acercarse al análisis historiográfico. En realidad, prefiero hablar de un conjunto heterogéneo de sugerencias. En lugar de considerar a Nietzsche como un autor, se trata de instrumentalizarlo, utilizarlo, despersonalizarlo en el sentido deleuziano del término. Para concluir, unas palabras de Deleuze que, creo yo, resumen bien la intención de este trabajo:

"Una teoría es exactamente como una caja de herramientas [...] es preciso que sirva, que funcione, y que funcione para otros, no para uno mismo. Si no hay personas que se sirvan de ella, comenzando por el propio teórico, que deja entonces de ser teórico, es que la teoría no vale nada, o que aún no llegó su momento [...] Es curioso que un autor que pasa por ser un intelectual puro, Proust, haya sido quien lo formuló con toda claridad: tratad mi libro como un par de lentes dirigidos hacia el exterior, y bien, si no os sirven, serviros de otros, encontrad vosotros mismos vuestras herramientas) ${ }^{75}$.

73 Idem, p. 52.

74 Idem, p. 53.

75 Deleuze, Gilles y Foucault, Michel (1972), "Los intelectuales y el poder", Estrategias de poder. Obras esenciales. Volumen II, Paidós, Barcelona, 1999, pp. 107-108. 